\title{
Diminished Polymorphonuclear Leukocyte Adherence and Chemotaxis following Protein- Calorie Malnutrition in Newborn Rats
}

\author{
MARY CATHERINE HARRIS, STEVEN D. DOUGLAS, JOO-CHIANG LEE, MORITZ M. ZIEGLER, \\ JEFFREY S. GERDES, AND RICHARD A. POLIN \\ Divisions of Neonatalogy, Allergy-Immunology-Pulmonology and Surgery of The Children's Hospital of \\ Philadelphia and the Department of Pediatrics of the University of Pennsylvania School of Medicine, \\ Philadelphia, Pennsylvania.
}

\begin{abstract}
Recent advances in neonatal care have permitted the survival of very low birth weight infants who are difficult to nourish, and ultimately develop clinical and biochemical signs of malnutrition. These infants may be at greater risk for nosocomial infection than normally nourished hosts. We have compared neutrophil adherence and chemotactic responses in a newborn rat model of proteincalorie malnutrition. Wistar rats at 14 days gestation received either a normal (24\% protein) or isocaloric $(2.5 \%$ protein) diet. On day 5, rat pups were divided into three groups: 1) pups allowed to nurse on their own dam (normal); 2) normally nourished pups foster nursed onto a malnourished mother (depleted); or 3) malnourished pups foster nursed to a normal dam (repleted). Granulocytes from depleted pups demonstrated significantly diminished adherence and chemotaxis when compared to normal or repleted pups. Thus, abnormalities of neutrophil function in malnourished newborn rats may contribute to increased susceptibility to bacterial infection. (Pediatr Res 21: 542 546,1987 )
\end{abstract}

\section{Abbreviations}

PMN, polymorphonuclear leukocyte

FMLP, N-formyl methionyl leucyl phenylalanine

HBSS, Hanks' balanced salt solution

PBS, phosphate-buffered saline

DMSO, dimethylsulfoxide

IP, intraperitoneally

Infection during the newborn period remains an important cause of morbidity and mortality, despite increasing sophistication in infant intensive care and the use of broad-spectrum antimicrobial agents (1-4). Most neonatal bacterial infections occur within the 1st wk of life as a result of exposure to maternal genital microorganisms during the intrapartum period (5-7). During the last decade, however, improved neonatal care has permitted the survival of a population of very low birth weight infants, who require hospitalization for extended periods of time and who are at increased risk for nosocomial infection $(8,9)$. These tiny babies have unique problems and are often quite

Received February 3, 1986; accepted January 2, 1987.

Correspondence and reprint requests: Mary Catherine Harris, M.D., Division of Neonatology, The Children's Hospital of Philadelphia, 34th Street and Civic Center Boulevard, Philadelphia, PA 19104.

Supported by Public Health Service Grants 1 Rol-HL-27068 and 1 PO1 NS17752 from the National Institutes of Health and the Biomedical Research Support Fund, The Children's Hospital of Philadelphia. difficult to nourish because of systemic illnesses such as respiratory distress syndrome or gastrointestinal tract immaturity. Many babies ultimately develop clinical and biochemical signs of malnutrition. Malnutrition during the immediate postnatal period may further compromise an already inadequate immune system and alter host susceptibility to infection $(10,11)$. Previous investigations have demonstrated abnormalities of both phagocyte and lymphocyte functions in older children with kwashiorkor (12). However, the effects of early postnatal malnutrition on polymorphonuclear leukocyte function have not been studied.

The purpose of this study is to compare granulocyte adherence and chemotactic responses to FMLP in a newborn rat model of protein-calorie malnutrition. We have investigated the effects of postnatal nutritional depletion and repletion on neutrophil function in newborn rats.

\section{METHODS}

Study population. Pregnant Wistar rats (Charles River Breeding Laboratories, Wilmington, MA) at 14 days gestation were divided into two experimental groups to receive either a standard 24\% protein diet (Purina Laboratory Chow, no. 5001, Purina, St. Louis, MO) or an isocaloric $2.5 \%$ protein diet (Ziegler Brothers, Gardners, PA). After 21 days gestation the mothers on the restricted diet delivered pups that were small for gestational age when compared to normally nourished pups. Rat pups were then divided into three groups on the 5th day of life: 1) pups allowed to nurse on their own dam (normal, $n=9$ groups); 2 ) normally nourished pups foster nursed onto a surrogate malnourished mother (depleted, $n=7$ groups); or 3) malnourished pups foster nursed to a normal lactating dam (repleted, $n=20$ groups) (Fig. 1) (13). All pups were weighed every 3 days and sacrificed on day 21 , prior to weaning from their respective dams. All pups were free from obvious infection at the time of study. Litters were adjusted for a maximal size of 12 animals. Pups malnourished both in utero and during the postnatal period did not live beyond 7 days and were not studied.

To obtain sufficient cells $\left(3 \times 10^{6} \mathrm{PMNs}\right)$ for functional assays, blood from rat pups in a single litter was pooled at the time of sacrifice. Therefore, the number of groups cited above refers to the number of rat experiments using pooled blood from the animals, e.g. the nine normal pup groups refer to nine experiments performed on approximately 50 animals. In the normally nourished or repleted pups, five to six rats yielded $8-9 \mathrm{ml}$ whole blood. In the depleted rat pup group an entire litter (10-12 pups) was sacrificed to obtain sufficient cells for each experiment. Malnourished adult rats $(n=9)$ were studied following $4 \mathrm{wk}$ of protein-calorie malnutrition and were compared to normally nourished adult rat controls $(n=14)$. In each experiment PMNs 


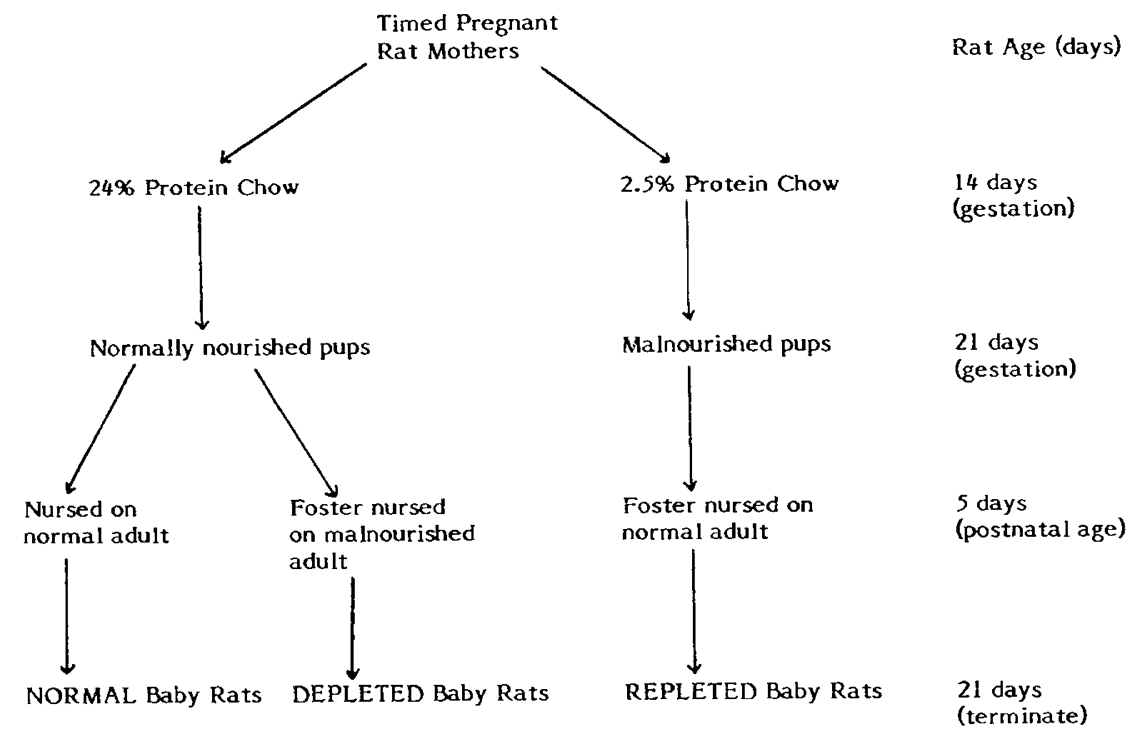

Fig. 1. Flow diagram of experimental design.

from rats were studied simultaneously with cells from an adult human control.

Preparation of rat PMNS. Following the intraperitoneal administration of $1 \mathrm{mg} / \mathrm{kg}$ pentobarbital, rats were bled by axillary slash, and blood collected into heparinized tubes. PMNs were separated on Ficoll-Hypaque gradients (Pharmacia Fine Chemicals, Piscataway, $\mathrm{NJ}$ ) at $800 \times g$ for $45 \mathrm{~min}$ at room temperature. After centrifugation the medium, leukocyte interface and FicollHypaque layer of the gradient were suctioned off leaving the neutrophil-red cell pellet. To lyse contaminating red blood cells, $36 \mathrm{ml}$ ice cold distilled water were added, the tube inverted for $30 \mathrm{sec}$ and $4 \mathrm{ml} 10 \times$ HBSS without $\mathrm{Ca}, \mathrm{Mg}$ added to the tube. The pellet containing PMNs was removed and washed twice in HBSS with $15 \mathrm{mM}$ Hepes at $400 \times g$ at $4^{\circ} \mathrm{C}$ for $10 \mathrm{~min}$. Cells were counted in $2 \%$ acetic acid and trypan blue and suspended to $1 \times 10^{6} \mathrm{PMNs} / \mathrm{ml}$. Cells suspensions characteristically contained greater than $95 \%$ viable PMNs.

Neutrophil adherence. Neutrophil adherence was determined in the resting state and following single $(10 \mathrm{nM})$ or sequential (5 $\mathrm{nM}, 10 \mathrm{nM}$ ) FMLP (Sigma, St. Louis, MO) stimulation for 10 min at $37^{\circ} \mathrm{C}(14) .2 \times 10^{5} \mathrm{PMNs}$ in $200 \mu \mathrm{l}$ of PBS were incubated on $15 \mathrm{~mm}$ diameter glass coverslips at $37^{\circ} \mathrm{C}$ for 10,20 , and 30 min (15). Coverslips were then washed and stained with Diffquick (Dade Diagnostics Inc., Aquada, Puerto Rico). The number of adherent PMNs on 10 random, but representative areas, was calculated using a $10-\mathrm{mm}$ square grid. Duplicate coverslips were counted blindly at each time point.

Neutrophil chemotaxis. Chemotaxis of freshly isolated PMNs was evaluated using a modified Boyden technique with blindwell chambers (Neuroprobe Inc., Bethesda, MD), $5 \mu$ micropore (polycarbonate/no PVP) filters (Millipore Corp., Bedford, MA), and FMLP as the chemoattractant. FMLP was dissolved in DMSO to an initial concentration of $0.01 \mathrm{M}$ and further diluted in PBS to form solutions of $10^{-4}$ to $0.5 \times 10^{-8} \mathrm{M}$. Twenty-five $\mu$ of FMLP or PBS control was placed in the bottom chamber of each chemodevice. A chemotaxis filter was placed over the lower chamber and incubated for $10 \mathrm{~min}$ at $37^{\circ} \mathrm{C}$. Fifty $\mu$ l of the PMN suspension $\left(2.5 \times 10^{4} \mathrm{PMNs}\right)$ were then placed into the upper chamber and the entire device incubated for $45 \mathrm{~min}$ at $37^{\circ}$ $\mathrm{C}$ in a humidified environment. Following chemotactic incubations, chambers were routinely examined to assure that neutrophils had not migrated through the filters into the bottom wells. The filters were removed, stained, mounted, and the number of migrating PMNs counted using a $10-\mathrm{mm}$ square grid. Each FMLP concentration was assigned triplicate wells, and five random areas were counted per well. The percent migration was determined as:

$$
\begin{aligned}
\% \text { migration }=[\text { cells FMLP }- \text { cells control }] \\
\qquad \times\left[\frac{128 \text { (area factor })}{2.5 \times 10^{4} \text { cells } / \text { well }}\right] \times 100
\end{aligned}
$$

Nutritional assessments. Immediately prior to sacrifice on day 21 , serum samples were obtained from neonatal and adult rats for measurement of albumin and fibronectin.

Albumin assay. Albumin concentrations were determined in rat serum (diluted 1:5) by standard nephelometry technique (16) with a reference curve ranging from $0.1-2.5 \mathrm{mg} / \mathrm{dl}$.

Fibronectin assay. Fibronectin concentrations were determined by a competitive ELISA previously described in our laboratory (17).

Milk collection. Rat breast milk was collected on day $21,4 \mathrm{~h}$ after lactating dams were separated from their offspring (18). Sixteen units $/ \mathrm{kg}$ of oxytocin were injected IP $5 \mathrm{~min}$ after pentobarbital $(30 \mathrm{mg} / \mathrm{kg})$ had been administered IP. Two minutes later, milk was collected by gently stroking the dam's breasts. Milk samples were frozen at $-70^{\circ} \mathrm{C}$, and total protein concentration was measured by the method of Lowry et al. (19) with bovine serum albumin as the standard control.

Statistics. Data from both immunologic and nutritional assays were analyzed using two-way repeated measures analysis of variance, and Student's two tailed independent $t$ test. Statistics were performed on the normally nourished, repleted, and depleted rat pups with $n$ being the number of pup groups or experiments performed.

\section{RESULTS}

Anthropometric data. As shown in Figure 2, pregnant female rats fed a $2.5 \%$ protein diet from day 14 of gestation delivered a population of newborn pups that were small for gestational age $(4.7 \pm 1.1 \mathrm{~g})($ mean $\pm \mathrm{SEM})$ versus normal pups $(8.0 \pm 0.3 \mathrm{~g})$. Foster nursing of normal pups on malnourished mothers (depleted rat group) produced animals whose mean weight at $3 \mathrm{wk}$ of age $(13.8 \pm 4.4 \mathrm{~g})$ was significantly less than normal $(37.8 \pm$ $1.2 \mathrm{~g})$ or repleted $(34.6 \pm 5.3 \mathrm{~g})$ animals $(p<0.001)$. In addition, daily weight gain over the 3 -wk period was significantly greater for the normal $(1.7 \pm 0.2 \mathrm{~g} /$ day $)$ and repleted pups $(1.8 \pm 0.4 \mathrm{~g} /$ day) when compared to the depleted rat pup group $(0.1 \pm 0.1 \mathrm{~g} /$ day) $(p<0.001)$. There was no significant difference in velocity of growth or mean weight at 21 days for the repleted or normal rat pups. 


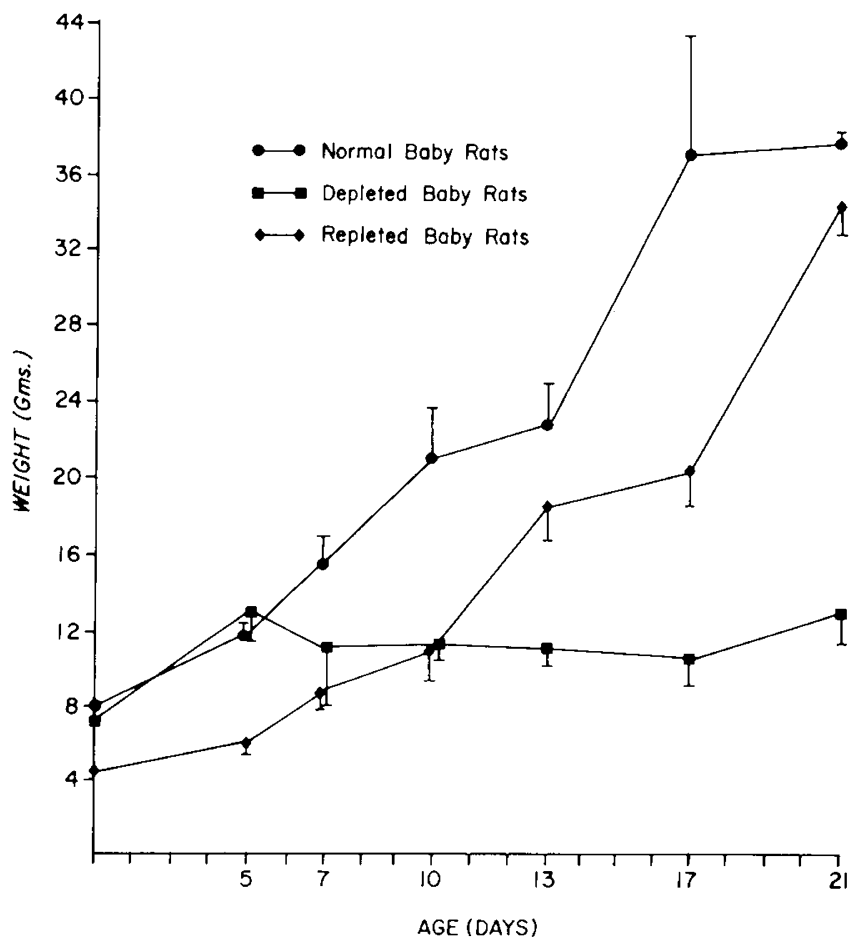

Fig. 2. Postnatal growth of baby rats (mean \pm SEM) depleted, repleted, and normal pups.

Neutrophil adherence. PMNs from depleted rat pups demonstrated significantly diminished adherence when compared to normal or repleted pups at 10,20 , and $30 \mathrm{~min}$ (Table 1). Neutrophils from repleted pups demonstrated intermediate adherence values. There were no significant differences in PMN adherence between malnourished and normally nourished adult rats at the time points examined. Furthermore, single or sequential FMLP stimulation did not increase the adherence of neutrophils from depleted, repleted, or normal pups or healthy adult controls (data not shown).

Neutrophil chemotaxis. PMNs from adult and baby rats responded to FMLP in a linear fashion with maximal chemotactic response at $10^{-4} \mathrm{M}$ FMLP. In contrast, granulocytes from human adults demonstrated maximal chemotaxis at $10^{-7} \mathrm{M}$ FMLP (data not shown).

PMNs from depleted rat pups demonstrated significantly diminished chemotaxis when compared to normal or repleted pups at $10^{-5}, 10^{-6}, 0.5 \times 10^{-6}$, and $10^{-8} \mathrm{M}$ FMLP $(p<0.05)$ (Fig. 3). There were no significant differences in PMN motility between normal and repleted pups, except at $0.5 \times 10^{-6}$ M FMLP $(p<$ 0.02 ). In addition, the chemotactic responses of PMNs from malnourished or normally nourished adult rats were not significantly different (data not shown) ( $p=\mathrm{NS})$. Random motility of PMNs was unaffected by nutritional status among the malnourished or normally nourished adult or pup groups.

Nutritional assessments. Serum albumin concentrations were significantly lower in depleted rat pups, when compared to normal and repleted pups at 21 days of age (Table 2). Repleted pups demonstrated intermediate albumin values, which were significantly greater than depleted pups and less than normal pups. There were no significant differences in serum albumin between malnourished and normally nourished adult rats. At 21 days of age, serum fibronectin values were not significantly different among depleted, repleted, and normal rat pups. Normally nourished adult rats, however, demonstrated serum fibronectin values that were significantly greater than malnourished adult rats. There was no significant difference in breast milk protein concentrations from malnourished mothers when compared to normally nourished dams (Table 2).
Table 1. Neutrophil adherence $\left(\times 10^{5} \mathrm{PMNS}\right)($ mean $\pm S E M)$

\begin{tabular}{llll}
\hline & $10 \mathrm{~min}$ & \multicolumn{1}{c}{$20 \mathrm{~min}$} & $30 \mathrm{~min}$ \\
\hline Depleted baby rats & $0.42 \pm 0.04^{*}$ & $0.37 \pm 0.04^{*}$ & $0.44 \pm 0.06^{*}$ \\
Repleted baby rats & $0.71 \pm 0.10$ & $0.69 \pm 0.08$ & $0.72 \pm 0.04$ \\
Normal baby rats & $0.94 \pm 0.06$ & $0.98 \pm 0.06$ & $1.05 \pm 0.06$ \\
Malnourished adult rats & $0.93 \pm 0.13$ & $1.02 \pm 0.09$ & $1.14 \pm 0.11$ \\
Normal adult rats & $1.18 \pm 0.10$ & $1.18 \pm 0.07$ & $1.22 \pm 0.06$ \\
\hline
\end{tabular}

${ }^{*} p<0.05$ depleted versus normal or repleted baby rats. $p=\mathrm{NS}$ repleted versus normal baby rats and malnourished versus normal adult rats.

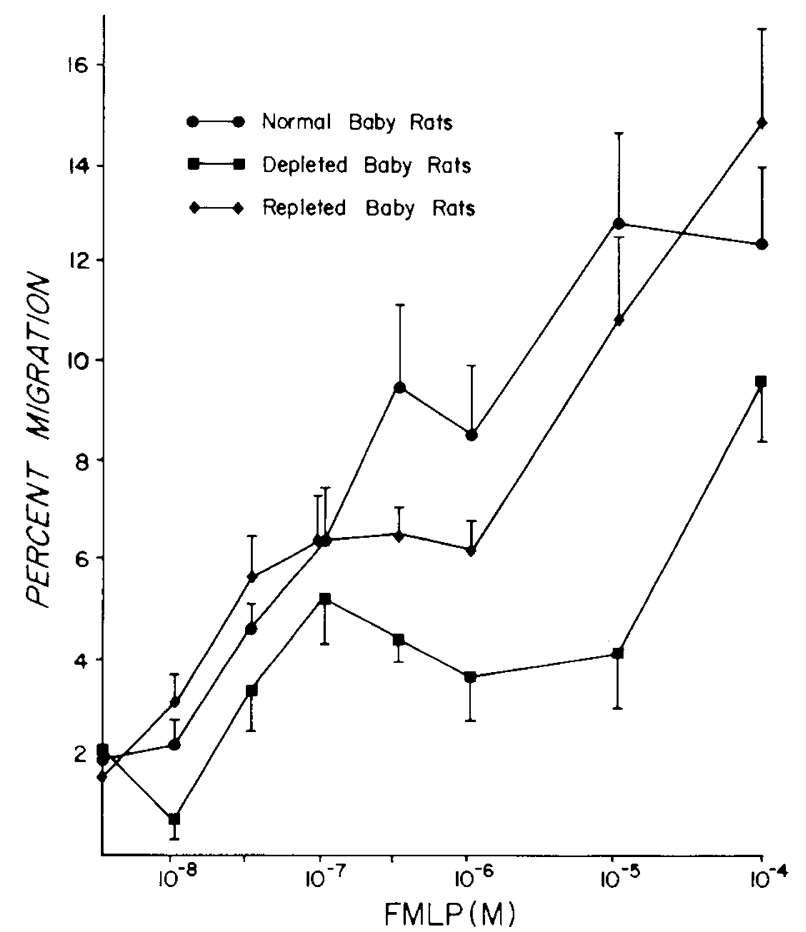

Fig. 3. Neutrophil chemotaxis (mean \pm SEM) depleted, repleted, and normal pups.

Table 2. Nutritional assessments (mean \pm SEM)

\begin{tabular}{llll}
\hline & $\begin{array}{c}\text { Albumin } \\
(\mathrm{g} / \mathrm{dl})\end{array}$ & $\begin{array}{c}\text { Fibronectin } \\
(\mu \mathrm{g} / \mathrm{ml})\end{array}$ & $\begin{array}{c}\text { Breast milk } \\
\text { protein } \\
(\mathrm{g} / \mathrm{dl})\end{array}$ \\
\hline Depleted baby rats & $2.45 \pm 0.06^{*} \dagger$ & $217.3 \pm 16.8$ & \\
Repleted baby rats & $3.56 \pm 0.30 \ddagger$ & $251.5 \pm 27.4$ & \\
Normal baby rats & $4.51 \pm 0.30$ & $220.6 \pm 16.3$ & \\
Malnourished adult rats & $3.74 \pm 0.49$ & $199.5 \pm 22.6 \S$ & $6.40 \pm 0.35$ \\
Normal adult rats & $4.21 \pm 0.24$ & $301.5 \pm 20.7$ & $7.07 \pm 0.52$ \\
\hline
\end{tabular}

Albumin values: $* \mathrm{p}<0.0001$ depleted versus normal baby rats; $\dagger \mathrm{p}$ $<0.05$ depleted versus repleted baby rats; $\ddagger \mathrm{p}<0.05$ repleted versus normal baby rats.

Fibronectin values: $\S p<0.01$ malnourished versus normal adult rats.

\section{DISCUSSION}

This study investigated the effects of postnatal nutritional depletion and repletion on neutrophil function in a newborn rat model of protein-calorie malnutrition. Following postnatal nutritional depletion, PMN adherence and chemotactic responses were severely depressed in rat pups. Depleted pups also developed biochemical signs of malnutrition, including significantly diminished serum albumin levels. Pups malnourished for 1 wk prior to delivery and subsequently foster nursed to normal lactating dams (repleted) demonstrated intermediate neutrophil adherence, chemotaxis, and albumin values. In adult rats, protein- 
calorie malnutrition did not affect albumin concentrations or significantly diminish neutrophil adherence or chemotactic responses. Breast milk protein concentrations were unaffected by maternal protein deprivation.

Malnutrition in older children and adult animals has been extensively studied $(14,20,21)$. Children with kwashiorkor demonstrate a secondary immune deficiency with increased susceptibility to infection and alterations in cellular, humoral, and phagocytic function (22). Studies by Schopfer and Douglas (12) in the Ivory Coast, West Africa demonstrated a significant delay in the chemotactic response of neutrophils from malnourished children in Boyden chambers, which normalized at longer incubation intervals. Granulocyte migration was further depressed during periods of infection. Sequential studies of malnourished beagle dogs demonstrated diminished neutrophil chemotactic responses toward Escherichia coli-derived chemoattractant, which were restored to normal values following total parenteral nutrition (23). These findings have been confirmed and extended by Anderson et al. (14) who studied neutrophil adherence and chemotaxis following FMLP or bacterial chemotactic factor stimulation. Neutrophils from malnourished children demonstrated diminished directed movement, enhanced baseline adhesion, yet an abnormal adherence response following stimulation with chemotactic factors. These abnormalities were reversed following nutritional restoration. In addition, there was no evidence of cell-directed inhibitors in the plasma or serum from the malnourished infants studied.

Few investigations of phagocyte function have been performed following intrauterine or early postnatal malnutrition. In neonates with intrauterine fetal growth retardation, Chandra (24) demonstrated diminished random and directed neutrophil motility, diminished nitroblue tetrazolium reduction, and decreased bactericidal capacity. Using a rat model of protein-calorie deprivation, Nwankwo et al. (11) recently demonstrated that rat pups malnourished during the neonatal period rapidly develop biochemical and immunologic signs of malnutrition. During experimental Staphylococcus aureus infection, malnourished pups demonstrated neutrophil depletion, and significantly increased infectious mortality.

In the current study, we have examined PMN functions (adherence and chemotaxis) previously demonstrated to be abnormal in studies of older, malnourished children (25). Our observations in the malnourished rat pup confirm the diminished granulocyte migration at shorter incubation intervals previously described by Schopfer and Douglas (12). It is not known whether our results reflect an abnormality of neutrophil kinetics as described in older children, or an intrinsic defect of PMN motility. We have not as yet investigated PMN chemotactic responses following longer incubation intervals.

PMNs from both healthy and malnourished rats respond to FMLP in a dose-dependent fashion with maximal chemotaxis at the highest FMLP concentration $\left(10^{-4} \mathrm{M}\right)$, while granulocytes from human adults demonstrate maximal motility at $10^{-7} \mathrm{M}$ FMLP. This finding suggests that there may be intrinsic differences in the structure of the rat neutrophil membrane, number or affinity of FMLP binding sites, or a relative insensitivity of the rat granulocyte to FMLP. Previous investigations of rat chemotactic responses during protein-calorie malnutrition have examined peritoneal macrophage function in weanling animals following stimulation with $E$. coli-derived chemoattractant $(26$, 27). We did not investigate rat PMN chemotactic responses following stimulation with other chemoattractants.

We observed that PMN adherence was significantly diminished in rat pups following postnatal protein deprivation and unchanged following preincubation with chemotactic factors. In contrast, Anderson et al. (14) recently demonstrated enhanced adherence and activated neutrophil morphology in malnourished pediatric patients. There are, however, several differences in study design, which may explain the conflicting results. These include nutritional and/or clinical status of the populations assessed (protein deprivation versus marasmus), the study population (rat versus human), age at the time of study (3 wk versus months to yr), nutritional differences perhaps related to specific nutrients, amino acids, or trace metals, and the specific laboratory methods employed.

Recent studies have suggested that fibronectin deficiency contributes to host defense depression during malnutrition. Following starvation, rats demonstrate a reduction in immunoreactive fibronectin, which is rapidly reversed following nutritional restoration $(28,29)$. Human volunteers manifest a similar reduction of plasma fibronectin in response to severe fasting (30). In the current study as expected, fibronectin values were significantly diminished in adult rats following $3 \mathrm{wk}$ of protein malnutrition. It is somewhat surprising, then, that depleted rat pups demonstrated normal fibronectin values when compared to agematched controls. However, fibronectin turnover may be different in newborn animals when compared to adult rats (31). In addition, the effects of protein deprivation on fibronectin synthesis may not be comparable to changes induced during periods of acute starvation. Fibronectin is also an important mediator of cell-to-cell and cell-to-substrate attachment. In the current study, abnormalities of neutrophil adherence and chemotaxis during malnutrition may be related to deficiencies of PMN cell surface fibronectin. However, we have not investigated neutrophil binding of fibronectin-coated microspheres or fibronectin receptors on neutrophils from malnourished animals.

The mechanism responsible for the diminished neutrophil adherence and chemotaxis in malnourished newborn rats is unknown. In studies of older malnourished children, Anderson et al. (14) suggested that altered neutrophil motile and adhesive properties in vitro may relate to cellular activation following prestimulation in vivo with chemotactic factors. Our findings of diminished adherence and a poor adherence response following FMLP stimulation in newborn rats differ from these observations of Anderson et al. (14) with hu, nan neutrophils. Neutrophil defects during malnutrition may occur at the receptor level, at the signaling or transduction levels, or in specific effector functions. Future studies should also determine whether these abnormalities result from selective, specific nutrient deficiencies during malnutrition and investigate both cellular and humoral contributions to neutrophil adherence and locomotion in malnourished newborn rats.

In the current study, maternal protein deprivation did not significantly affect the protein content of breast milk after $3 \mathrm{wk}$ of lactation. However, as reported previously, the primary effect of protein-energy malnutrition is a reduction in the quantity of milk produced rather than a change in protein concentration $(12,32)$. Fellows and Rasmussen (33) recently reported increased protein values in breast milk from malnourished dams. In these studies, pumped milk samples had higher protein and fat concentrations because they were excessively dehydrated. Therefore, the method used to obtain breast milk (pumped versus nursed samples) may significantly affect protein determinations. In addition, the influence of dietary protein and energy on milk secretion can be inferred from rat pup weight gain $(18,32)$.

We have demonstrated that host defenses are rapidly compromised by malnutrition during the neonatal period. Further, these defects are reversible following nutritional restoration. Although relevant investigations have not been performed in human neonates, we speculate that there is a relationship between in vitro abnormalities of PMN function during protein-calorie malnutrition and the enhanced susceptibility to nosocomial bacterial infection.

Acknowledgment. The authors thank Barbara Erwins for editorial assistance.

\section{REFERENCES}

1. Harris MC, and Polin RA 1983 Neonatal septicemia. Pediatr Clin North Am $30: 243-258$ 
2. McCracken GR J 1981 Perinatal bacterial diseases. In: Feigen RD, Cherry JD (eds) Textbook of Pediatric Infectious Diseases. WB Saunders Company, Philadelphia, pp 747-768

3. Miller ME 1978 Phagocytic cells. In: Oliver TK (ed) Host Defenses in the Human Neonate. Grune and Stratton, New York, pp 59-71

4. Siegel JD, McCracken GH Jr 1981 Sepsis neonatorum. N Engl J Med 304:642647

5. Baker CJ 1980 Group B streptococcal infections. Adv Intern Med 25:475-501

6. Boyer KM, Gadzala CA, Kelly PD, Gotoff SP 1983 Selective intrapartum chemoprophylaxis of neonatal group B streptococcal early onset disease. III. Interruption of mother-to-infant transmission. J Infect Dis 148:810-816

7. Klein JO and March SM 1976 Bacterial sepsis and meningitis. In: Remington $\mathrm{J}$, Klein JO (eds) Infectious Diseases of the Fetus and Newborn Infant. WB Saunders Company, Philadelphia, pp 679-735

8. Baker CJ 1981 Nosocomial septicemia and meningitis in neonates. Am J Med 70:698-701

9. Goldman DA 1981 Bacterial colonization and infection in the neonate. Am J Med 70:417-422

10. Gross RL, Newberne PM 1980 Nutrition and immunologic function. Physiol Rev 60:188-302

11. Nwankwo MU, Schuit KE, Glew RH 1985 Effects of maternal protein deprivation on the nutritional status and neutrophil function of suckling neonatal rats. J Infect Dis 151:23-32

12. Schopfer K, Douglas SD 1976 Neutrophil function in children with Kwashiorkor. J Lab Clin Med 88:450-46

13. Howell CG, Ziegler MM, Vega A, Robinson M 1983 Neonatal malnutrition: an underlying etiology of necrotizing enterocolitis. Current Surg 40:17-19

14. Anderson DC, Krishna GS, Hughes B, Mace ML, Nichols BL, and Smith CW 1983 Impaired polymorphonuclear leukocyte motility in malnourished infants: Relationship to functional abnormalities of cell adherence. J Lab Clin Med 101:881-895

15. Harris MC, Levitt J, Douglas SD, Gerdes JS, Polin RA 1985 Effect of fibronectin on adherence of neutrophils from newborn infants. $\mathrm{J}$ Clin $\mathrm{Mi}$ crobiol 21:243-246

16. Lizana J, Hellsing TK 1974 Manual immunonephelometric assay of protein with the use of polymer enhancement. Clin Chem 20:1181-1187

17. Gerdes JS, Douglas SD, Kolski GB, Yoder MC, Polin RA 1984 Decreased fibronectin biosynthesis by human cord blood mononuclear phagocytes in vitro. J Leuk Biol 35:91-99

18. Crinic LS, Chase H 1978 Models of infantile undernutrition in rats: effects on milk. J Nutr 108:1755-1760
19. Lowry OH, Rosenbrough NJ, Farr AL, Randall RJ 1951 Protein measurements with the folin phenol reagent. J Biol Chem 193:265-275

20. Chandra RK 1981 Immunocompetence as a functional index of nutritional status. Br Med Bull 37:89-94

21. Douglas SD, Schopfer K 1977 The phagocyte in protein-calorie malnutrition In: Suskind RM (ed) Malnutrition and the Immune Response. Raven Press New York, pp 231-243

22. Good RA, West A, Fernandez G 1980 Nutritional modulation of immune responses. Fed Proc 39:3098-3104

23. Dionji R, Zonta A, Dominoni L, Gres F, Ballabia A 1977 The effects of total parenteral nutrition on immunodepression due to malnutrition. Ann Surg 185:467-474

24. Chandra RK 1975 Fetal malnutrition and postnatal immunocompetence. Am J Dis Child 129:450-454

25. Douglas SD, Faulk WP 1977 Immunologic aspects of protein-calorie malnutrition. In: Thompson RA (ed) Recent Advances in Clinical Immunology. Churchill Livingstone, New York, pp 15-39

26. Keusch GT, Douglas SD, Braden K, Geller SA 1978 Antibacterial functions of macrophages in experimental protein-calorie malnutrition. I. Description of the model, morphologic observations and macrophage surface IgG receptors. J Infect Dis 138:125-133

27. Keusch GT, Douglas SD, Hammer G, Braden K, 1978 Antibacterial functions of macrophages in experimental protein-calorie malnutrition. II. Cellular and humoral factors for chemotaxis, phagocytosis, and intracellular bactericidal activity. $J$ Infect Dis 138:134-142

28. Dillon BC, Saba TM, Cho E, Lewis E 1982 Opsonic fibronectin deficiency in the etiology of starvation-induced reticuloendothelial dysfunction. Exp Mol Pathol 36:177-192

29. Saba TM, Dillon BC, Lanser ME 1983 Fibronectin and phagocytic hos defense: Relationship to nutritional support. JPEN 7:62-68

30. Howard LJ, Dillon BC, Hoffman SL, Cho E, Saba TM 1981 Plasma fibronectin (opsonic glycoprotein) as an index of nutritional deficiency and repletion of human subjects. JPEN 5:558(abstr)

31. Polin RA, Yoder MC, Douglas SD, McNelis W, Nissim I, Yudkoff M 1986 Quantitation of fibronectin turnover in the premature human neonate using $\left({ }^{15} \mathrm{~N}\right)$ glycine. Pediatr Res 20:417A(abstr)

32. Sampson DA, Jansen GR 1984 Protein and energy nutrition during lactation. Ann Rev Nutr 4:43-67

33. Fellows WD, Rasmussen KM 1984 Comparison of methods for obtaining milk samples from well-nourished and malnourished rats. Physiol Behav 33:761763 